for with special attention this year, as the shower is supposed to owe its parentage to Halley's comet. The latter is approaching the sun rapidly, and will probably be discovered next September.

"Should the meteors prove to be unusually abundant this year and in 1910, the fact may be accepted as conclusive evidence that they are directly associated with Halley's comet. Experience has proved that meteors may swarm in front of a parent comet as well as behind it. Prof. Newton pointed out that the Andromedid meteors precede Biela's comet to a distance of 300 millions of miles along the orbit.

"At Greenwich the radiant of the Aquarids does not rise until about 1.30 a.m., so that observations will be useless before that time, and there is only a short interval left for effective watching, for daylight has so far advanced at $3 \mathrm{a} . \mathrm{m}$. that only really conspicuous meteors can be observed. This year the moon will be full, and her strong light will obliterate the fainter meteors, but the Aquarids are generally pretty bright, with long flights of 40 or 50 degrees, so that should the shower abundantly return this year it may be expected to present a striking aspect, notwithstanding the presence of our satellite."

Comet Morehouse, $1908 \mathrm{c}$.- This comet was observed by Prof. F. Ristenpart at Santiago de Chile on March 28 and 30 , and the observations show that, on these dates, the ephemeris published by Herr Ebell in No. 4296 of the Astronomische Nachrichten required corrections of $+2 \mathrm{~m}$. 2s., $-\mathrm{r} \cdot \mathrm{O}^{\prime}$, and $+\mathrm{Im} .43 \mathrm{~s} .,-2 \cdot 2^{\prime}$, respectively (Astronomische Nachrichten, No. 4318 ).

The "Original" Canals of thie Martian Doubles.Usually the twin lines forming the double canals on Mars are equally intense, but on occasions one line appears to be more conspicuous than its fellow. The reduction of Prof. Lowell's 1907 observations shows that, with one or two exceptions, it is always the same canal of any pair that becomes weakened, sometimes to extinction.

A table given in Bulletin No. 37 of the Lowell Observatory shows that. of twenty-two double canals observed during the opposition of 1907 , eighteen definitely presented the phenomenon of unequal intensities. Of these, sixteen always showed the one line of the pair, the "original" canal as Prof. Lowell names it, stronger than the other the period of observation covered the epoch of minimum visibility of the doubles.

The two exceptional canals were the Gihon and the $I s$, and in both cases there is a possible explanation of their apparently anomalous behaviour. For the former this depends upon the fact that when the eastern line was the stronger the canal was still being fed from the north polar cap, whilst when the western line preponderated the canal was sharing in the general southern darkening of the canals of the southern hemisphere. A similar explanation holds in the case of Is. Comparisons with Schiaparelli's observations confirm the phenomenon.

Chromospheric Calcium Lines in Furnace Spectra.In No. 32 of Contributions from the Mount Wilson Solar Observatory Dr. A. S. King discusses the behaviour of the calcium lines $\mathrm{H}, \mathrm{K}$, and $\lambda 4227$ in the spectrum obtained by heating calcium to various temperatures, and under varying conditions of density, in the electric furnace.

His experiments at the Pasadena laboratory show that whilst the line 4227 appears at a low temperature, and is not sensitive to increases of temperature, it is enormously strengthened by increasing the amount of calcium vapour present. On the other hand, $\mathrm{H}$ and $\mathrm{K}$ do not appear until the temperature approaches $2500^{\circ} \mathrm{C}$., and are very sensitive to temperature variation, whilst but little affected by increasing the quantity of calcium vapour.

Dr. King points out that although these results do not throw much light on the study of sun-spot spectra, they are in strict accordance with eclipse observations of the chromosphere. $\mathrm{H}$ and $\mathrm{K}$ appear alone in the higher tegions of prominences, but $\mathbf{4 2 2 7}$ does not appear until the chromospheric vapours reach a considerable density.

Mount Wilson Solar Observatory Report.-Prof. Hale's report of the work done at the Mount Wilson Observatory during $190 \mathrm{~S}$ is too compendious to notice in detail, and many of the results mentioned have already No. $206 \mathrm{I}$, voL. 80$]$ been abstracted in these columns, but there are one or two points which may be mentioned. Prof. Hale states that the electric-furnace experiments have confirmed the conclusion that the temperature of the vapours of $\mathrm{Fe}, \mathrm{Ti}$ \&c., in sun-spots is lower than that in the "reversing layer " outside spots.

Mr. Abbot, of the Smithsonian Institution, is still engaged in the studies of the solar constant, and arrangements have been made by the institution to construct a permanent station on Mount Wilson, where such studies will be regularly maintained. The total number of spectroheliograms taken with the 5 -feet spectroheliograph amounted to 5196 on September 30, 1908 .

An investigation dealing with the absorption and scattering of light in the solar atmosphere has just been completed by Prof. E. F. Nichols, of Columbia University, and the observations are in course of reduction.

A spectrocomparator has been added to the laboratory equipment, and is being used for the comparison of the intensities of spectrum lines. The definite reduction of the photographic sun-spot spectra is being carried out, and some idea of the magnitude of the task is afforded by the statement that between $\lambda 5000$ and $\lambda 5500$ there are more than 1500 lines for which wave-lengths and laboratory identifications have to be determined.

\section{THE ELECTRIFICATION OF RAILWAYS.}

THE presidential address delivered by Mr. John A. F. Aspinall in the lecture hall of the Institution of Mechanical Engineers on Friday, April 23, proved to be a most agreeable surprise to those members who were fortunate enough to be present. Addresses on such occasions are apt to take a historical or academical form, and many experiences of this character served to emphasise the interest taken by the audience in Mr. Aspinall's clear account of the electrification and experiences gained in the working of the Liverpool and Southport branch of the Lancashire and Yorkshire Railway, of which the author is the distinguished head, since its inception in October, 1902.

It is too often stated that a general electrification of our railways would be of very great advantage. In certain instances this work can be undertaken with great commercial success, but each case has to be considered with great care, not only on account of the costly character of the work, but also because the conditions upon which success or failure depend vary in almost every place or district. To warrant the electric equipment of a main line of railway, dealing in present circurnstances with long stcam-hauled trains at high speed for long distances without a stop, some great commercial advantage must be shown. Business men can easily arrange their journeys at present between Liverpool or Manchester and London so as to have five hours in town. Even supposing a speed of 120 miles per hour to be attained by electric traction, the gain to the traveller would be small, while the increased cost to the railway would be enormous. Again, such fast trains would practically prohibit the use of the same tracks for the running of slower local trains, and would neccssitate separate tracks for these. The earning capacity of the express tracks would thus be diminished.

On the other hand, in the case of many suburban lines from our great cities, electrification will at once double the train-carrying capacity of the tracks, while in others it will allow a greater time space between trains, which may be utilised for the passage of steam-worked express trains coming in from the more distant parts of the line. In a district where a railway has had its tracks paralleled by tramways, the creation of an electric railway service will have the immediate effect of bringing back large numbers of passencers who have used the trams in the early stages of their construction, but who find that they cannot tolerate the great waste of time which results from the very slow speed and the many stops due to the crowded streets through which the trams have to run. Some of the advantages of electrification for local services are :-
(a) High schedule iourney speed.
(b) Much more frequent service when required.
(c) Increased acceleration and deceleration. 
(d) Greater possible mileage per train per day, increas. ing the earning capacity of any given quantity of rolling stock, and increasing the loading and unloading capacity of existing platforms.

The Southport branch of the Lancashire and Yorkshire Railway has proved to be a commercial success under electric working. It consists of a coast line of $18 \frac{1}{2}$ miles, having fiftcen stations. The total length of electrified line in the district amounts to four miles of four tracks and twenty-five miles of double tracks, making a total of seventy miles of single track, including sidings. It has been found possible to run all the passenger traffic on the double track on the section having four tracks, leaving the other double track free for goods traffic, thus enabling several stations on the goods track to be closed. The line is considered to provide the fastest service of this character in existence. Stopping trains run $18 \frac{1}{2}$ miles, stop fourteen times, and do the journey in thirty-seven minutes. Express trains run the same distance in twentyfive minutes.

During the transition stage from steam to electrical working there came a period when it was necessary to run steam trains in between the electrical trains at the same speed in order to keep them out of the way of the latter. An opportunity was thus afforded of comparing the coal consumption of the locomotives and the power house, and it was found that the six-wheeled coupled tank engines which did the work in 1904 consumed $80 \mathrm{lb}$. of coal per train mile with express trains, and roo $\mathrm{lb}$. with stopping trains. The consumption of coal at the power station in 1908 works out at $49 \mathrm{lb}$. per train mile for the electrical trains.

The time necessary for the conversion from steam haulage to electric traction is of importance. In the case of the line under discussion, the order for commencing the work of electrification was given on October 22, 1902, and the work was finished and the steam trains entirely withdrawn on May 13, I904.

After considering the questions of the wear in third and fourth rails, Mr. Aspinall dealt with the important matter of the excessive wear of track rails in electrical working. In his opinion, the special rails introduced by Sandberg were not the real cure. The real fault is one of construction. The more or less modern motor truck has all the defects of the older-fashioned locomotives on account of the low position of the centre of gravity. The modern steam locomotive with a high centre of gravity is a very easy riding machine. A motor-car, with its four axles, has a total weight of 12 tons, which is not carried by the springs. Raising the centre of gravity so as to enable this weight to be spring-borne would introduce additional mechailism, and would also block up the passages from car to car. The great advantages of direct drive would be lost, and as the present gears run extremely well it may be a more commercial method to wear out the cheap rail instead of expensive mechanism.

The cars on the Southport line are 60 feet long, and have large side doors at each end. These doors are opened or closed by the public themselves, who, by a bye-law sanctioned by the Board of Trade, are required to enter the car by the rear door and leave by the front door. This system requires a smaller platform staff, but as the larger number of electric trains requires more guards, the total number of men employed remains the same. During the rush hours the cars are emptied in fifty seconds at terminal stations, while intermediate stops consume fifteen seconds only.

Mr. Aspinall favours overhead conductors wherever possible. In the particular case of the high-tension line connecting Aintree with Seaforth, the cost per mile of the overhead equipment was $1300 l$, , while the cost per mile of the cable line was $2030 l$.

It was decided in 1905 to install battery plants; the general idea was to provide for running the whole railway for one hour in the event of any serious accident at the central generating station. The battery substations are placed at points intermediate to the rotary substations, and have had the effects of reducing the momentary peaks in the load from a maximum of $7000 \mathrm{kw}$, to $4500 \mathrm{kw}$. and the hourly peak during the rush hours from $3800 \mathrm{kw}$. to $3100 \mathrm{kw}$, enabling the load to be carried during the No. 2061 , VOL. 80$]$ winter with $4500 \mathrm{kw}$. of plant, and during the summer with $375^{\circ} \mathrm{kw}$. of plant.

The total over-all efficiency was found in July, Igo6, to be 8 I per cent. from the alternating current bus bars to the circuit breakers on the trains. The coal burned at the power house per unit of direct current delivered to the third rail, including all conversion losses, amounted to 3.28 lb. for the twelve months ending December 15, 1908.

In 1907 the Aintree line was electrified, and has led to the recovery of much of the traffic which had been taken away by the Municipal Tramways, which run parallel to the railway. On Grand National Day the race traffic on this section amounts to 13,000 people in about $2 \frac{3}{4}$ hours.

$\mathrm{Mr}$. Aspinall estimates that any railway company having. facilities for putting its own plant down in the country, with opportunities of getting cheap coal and water, should be able to produce current at the generating stations at a "works cost" of 0.25 penny per B.T.U. A high-speed" service could then be worked at a cost of $9.5 d$. per train mile. No amount for depreciation, other than battery depreciation, is included in this, or for interest on outlay. The figure does not include the maintenance of running track and stations, costs of platform staff, or other items common to both steam and electric lines. The great economy to be hoped for in the future for electrical railways, where no water power is available, is in the production of electricity in very large quantities; the total current-producing charges amount to the large proportion of $4.52 \mathrm{~d}$. out of the above-mentioned $9 \cdot 5 \mathrm{~d}$. Other possible economies are in the direction of such improved design in the motors as will lead to less repairs and a very careful consideration of the whole design of the motor truck. Items which may be put down as giving no trouble whatever are controllers, commutators, steel spur-gearing, and the third rail.

Mr. Aspinall looks forward to the opportunity which he hopes to afford members of the institution during the summer meeting at Liverpool of seeing the Liverpool and Southport line at work. The proceedings terminated with a hearty vote of thanks to the president for his interesting and valuable address, moved by Sir Wm. White, K.C.B., and supported by Mr. W. H. Maw.

There are ten appendices, with curves and photographs, giving minute information regarding the working of this line. of railway.

\section{SOME RECENT PALAEONTOLOGICAL PAPERS}

THE description of the fossil flora of Tegelen-sur-Meuse, near Venloo, in Holland, by Clement Reid, F.R.S., and Eleanor M. Reid (Verhandel. d. kon. Akad. van Wetenschappen te Amsterdam, September, 1907), is remarkable as showing how skilfully devised methods of observation will reap a rich harvest from " a box of clay easily carried by a man." The specimens of seeds washed or floated out of this Pliocene clay were temporarily preserved in formalin or salicylic acid; they were then washed in water, and each was placed, still wet, on a film of paraftin wax on a glass slide. The plate was immediately warmed from below, and the paraffin rose to take the place of the water evaporated from the seed. The surface could be cleaned with benzina and the seed was now so tough that it could be easily handled. The Tegelen flora indicates a stage just earlier than that of the Cromer Forest bed.

An illustrated paper on historic fossil cycads, by G. R. Wieland (American Journal of Science, vol. xxv., 1908, p. 93), directs attention to new points in some of the great cycad stems and casts in the museums of Europe. The type Cycadeoidea etrusca in Bologna is a silicified stem that was used as a sharpening stone in an Etruscan city some 4000 years ago, and it is claimed as " the most anciently collected of all geological specimens."

From Japan come two papers on fossil plants (Journal of the College of Science, Tokyo, vol. xxiii., 1908, articles 8 and 9). In the former, M. Yokovama describes spoils of war, in the form of Upper Carboniferous plants collected during the recent campaign in Manchuria. In the latter, $\mathrm{H}$. Yabe, whose work on Fusulina has been previously noticed in NATURE, shows how the occurrence of Giganto- 